\title{
OKLAHOMA DECIDUOUS TREES DIFFER IN CHILLING ENHANCEMENT OF BUDBURST
}

\author{
Stanley A. Rice \\ Department of Biological Science \\ Southeastern Oklahoma State University \\ Durant, OK 74701 \\ srice@se.edu
}

\author{
Sonya L. Ross \\ Physical Plant Department \\ Southeastern Oklahoma State University \\ Durant, OK 74701 \\ sross76@se.edu
}

Keywords: climate change, phenology

\begin{abstract}
In many tree species, winter chilling accelerates budburst in response to spring warmth. Global climate change has already accelerated budburst in deciduous tree species around the world. But as global climate change leads to milder winters, trees species also experience less chilling, which may actually delay spring budburst in some species. We hypothesized that reduced duration of winter chilling would delay spring budburst in sycamore (Platanus occidentalis) and pecan (Carya illinoinensis), but would not delay it in sweetgum (Liquidambar styraciflua). We tested this hypothesis experimentally by manipulating the number of weeks of chilling from 0 to 6 weeks. Lack of winter chilling did not delay budburst in sweetgum but did delay it in sycamore and pecan, in agreement with the hypothesis. Mild winters in Oklahoma may eventually favor the growth of sweetgums at the expense of sycamores and pecans.
\end{abstract}

\section{INTRODUCTION}

Earlier spring budburst in deciduous trees is widely recognized as one of the consequences of global climate change. It has been occurring for the last century and a half and has continued in recent decades (Schwartz et al. 2006; Ibañez et al. 2010; Polgar and Primack 2011). This conclusion is based upon several sources of information: comparison of recent with historical budburst dates, including the records of Henry David Thoreau at Walden Pond, and comparisons of recent with historical herbarium specimens and photographs (Primack et al. 2004; MillerRushing et al. 2006; Primack 2014); satellite imagery during recent decades (Liang et al. 2011); yearly records of individual woody plants during recent decades (Schwartz 1994; Rice and Schwartz, in prep.); and functional models (e.g. Morin et al. 2009).
The first author of this paper has maintained an ongoing record of budburst times for about 400 individuals of 22 deciduous tree species in Durant, Oklahoma, starting in 2006. By observing each tree at least weekly, and usually more often, the first author determined budburst date for each individual using a protocol similar to that of the Globe program (Globe.gov 2014). The data clearly indicate earlier budburst during the nine-year period, particularly from 2008-2012, during which time several tree species advanced their budburst time about two days per year. This did not occur in all species, however. In particular, budburst did not change in American elm (Ulmus americana L.) and became later each year in silver maple (Acer saccharinum L.), probably in association with summer drought and heat damage that either directly, or indirectly through pathogens, killed many of these trees (Rice and Schwartz, in prep). 
It is, however, invalid to extrapolate the trend toward earlier budburst for most tree species, because many woody species benefit from chilling for timely budburst (Schwartz and Hanes 2010). Chilling induces the development of structures within buds and/or alters the concentration of plant growth substances such as cytokinins (Hewett and Wareing 1973), a process sometimes called vernalization. If winters in some areas (such as southern Oklahoma) become brief and warm, the buds of some species may experience insufficient chilling and therefore reduced fitness (Luedeling et al. 2011). Some tree species also require a minimum daylength for budburst (e.g., Heide 1993a).

In general, we would expect tree species that open their buds early in the spring to have floral and vegetative structures already well-formed within the buds prior to winter, while these structures may have to develop during the winter in tree species that open their buds later in the spring. The tree species in the latter group may require chilling to initiate and complete the process of bud development. We therefore hypothesized that tree species that open their buds early in the spring do not have as much chilling enhancement of budburst as tree species that open their buds later in the spring. Specifically, we expected a negative association between time of budburst and chilling enhancement. We used three species to test this hypothesis in Oklahoma: sweetgum (Liquidambar styraciflua L., Altiginaceae), which opens its buds earliest of these three species, often in February; sycamore (Platanus occidentalis L., Platanaceae), which opens its buds later, often in March; and pecan (Carya illinoinensis (Wangenh.) K. Koch, Juglandaceae), which opens its buds last of these three species, often in April.

Numerous studies have examined the effect of chilling on budburst, but most of these studies have been conducted at higher latitudes (e.g., Hunter and Lechowicz 1992;
Heide 1993b; Chuine 2000). We wanted to test the hypothesis using Oklahoma trees, which may differ genetically from trees of the same species that live in other locations. For example, research in other parts of the world show that trees such as pecans (Kuden et al. 2013) have a chilling enhancement of budburst, but we cannot conclude from this that Oklahoma trees of these species have a similar chilling enhancement.

\section{METHODS}

We selected five individual trees at least 10 meters in height that are in the long-term data set from each of the three species. All were in parks or along streets in Durant, Oklahoma (Fig. 1). We originally also included post oak (Quercus stellata Wangenh.), but mortality of twigs during the experiment reduced the sample size to only one twig in two of the treatments.

From each tree, we obtained six twigs with intact terminal and axillary buds, two for each of the three chilling treatments described below, resulting in 30 twigs for each species (total of 90 twigs). We gathered twigs on 18 November 2013, after leaf senescence was well advanced but before the first frost. We labeled all twigs with masking tape. For each tree, we placed two twigs in a plastic food storage container with wet paper towels and stored them in a refrigerator at about $10^{\circ} \mathrm{C}$ for three weeks, and we stored two other twigs for six weeks. Six weeks is considerably less than the average of approximately 18 weeks between first (about November 9) and last (about March 28) frost during the previous four decades in Durant, Oklahoma (Fig. 2). At the end of chilling, we removed the twigs and placed them in warm conditions to allow budburst to begin. We also placed two twigs from each tree immediately into warm conditions ( 0 weeks). These unchilled twigs were the control. The warm conditions were in a temperature-controlled laboratory 
(Fig. 3). We also changed the water and cleansed the cut ends of the twigs with a brush to prevent decomposers, living off of sap, from blocking the xylem. Eighteen of the original 90 twigs failed to burst their buds during this experiment and were presumed dead. checked each twig at least twice a week for signs of budburst, defined as green tissue showing through separated bud scales

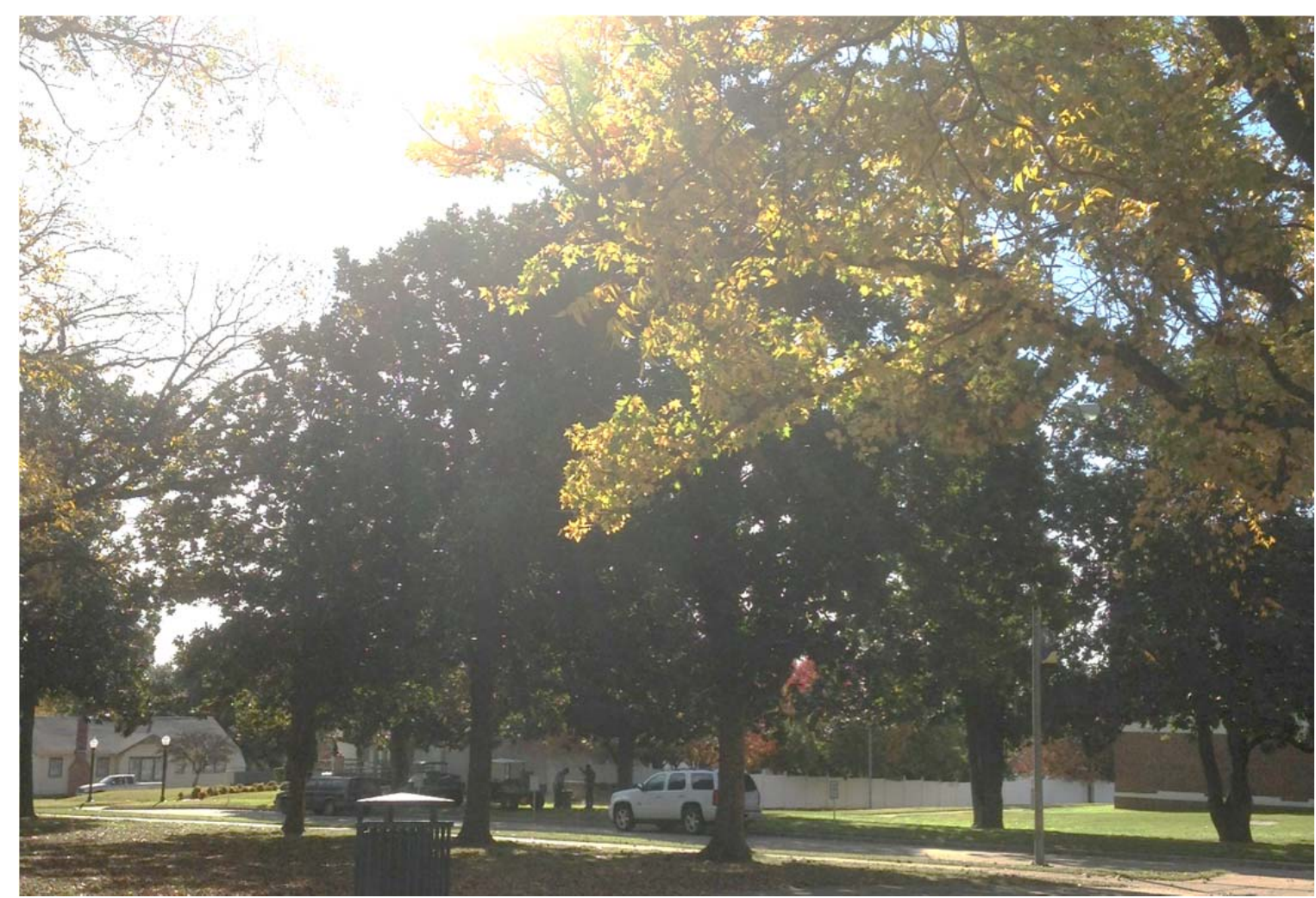

Figure 1 The general habitat of the trees used in this study in November 2013 


\section{- Durant}
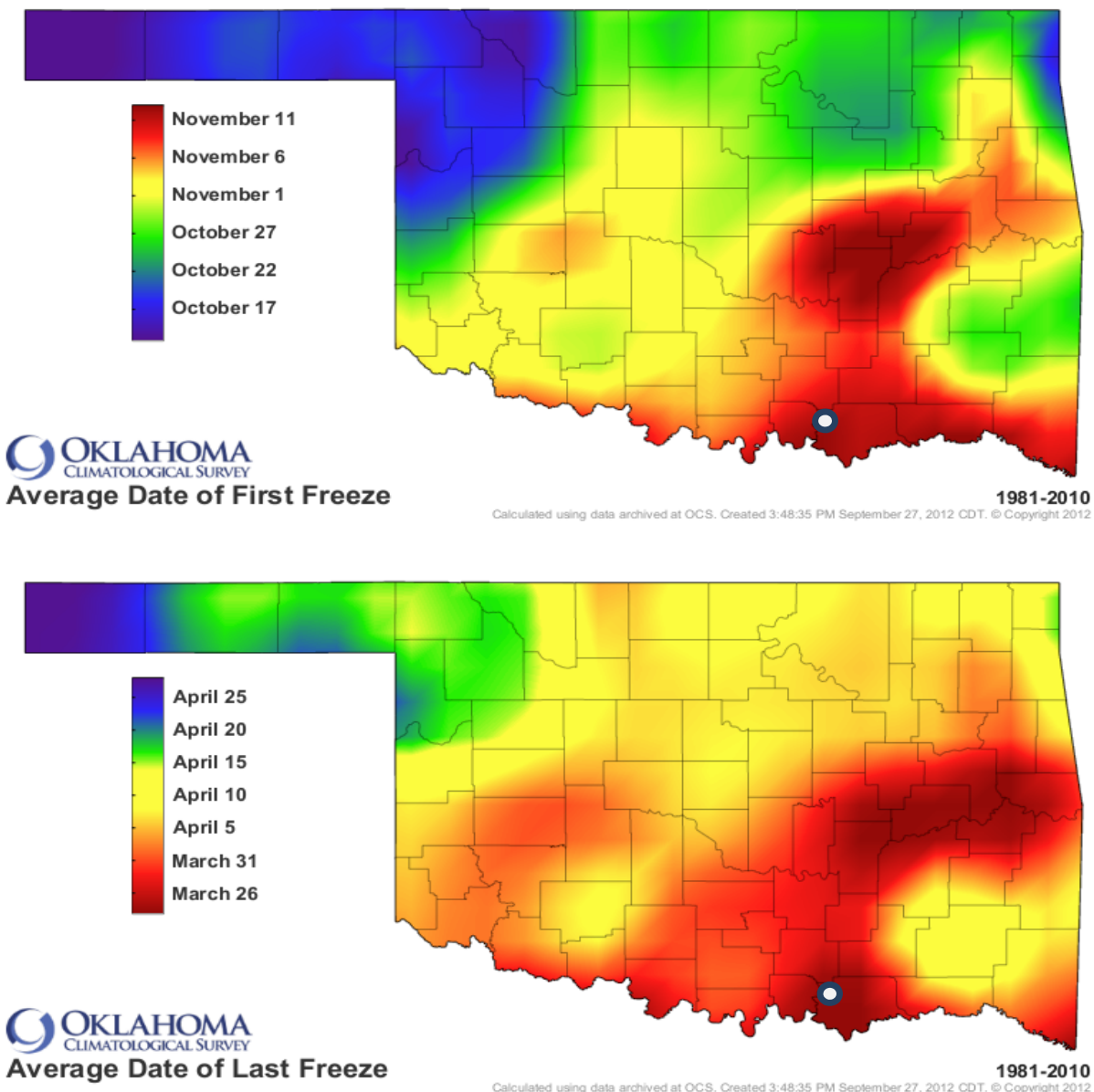

Figure 2 Average first and last freeze dates in Oklahoma, 1961-2010 average. Maps modified and used with permission from Oklahoma Climatological Survey (http://climate.ok.gov/index.php/climate).

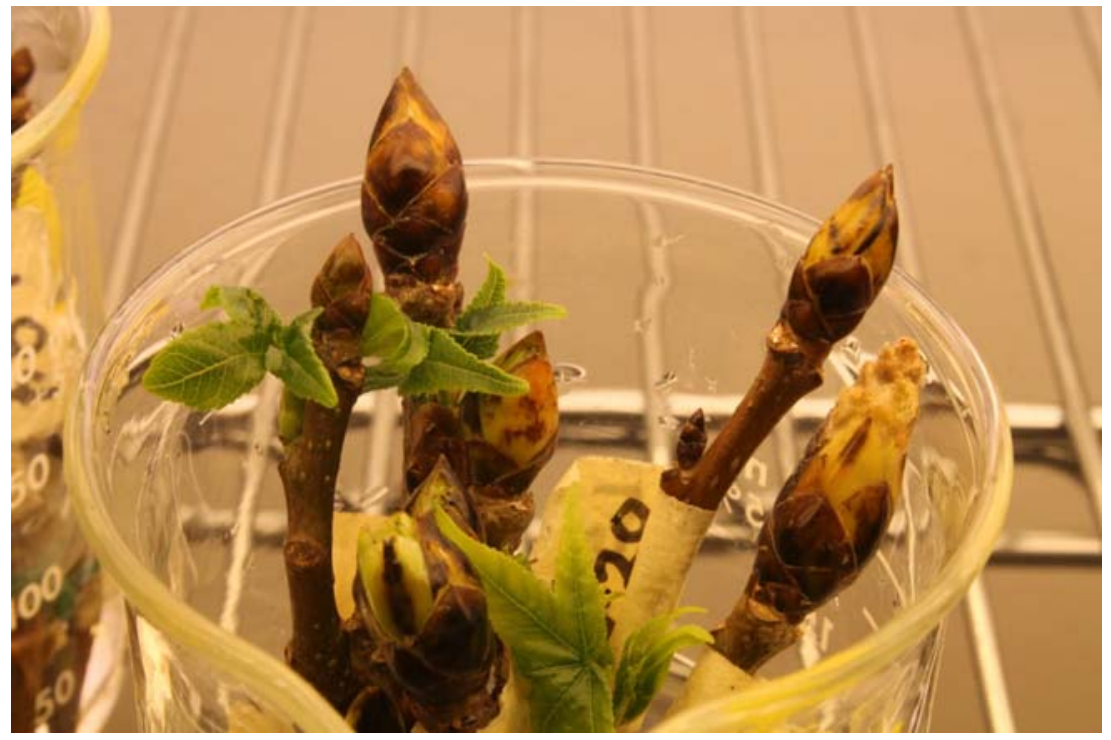

Figure 3 Buds of sweetgum (Liquidambar styraciflua) at various stages of budburst. The top bud has not yet opened, and the bud at the lower right is just beginning to open. 


\section{RESULTS AND DISCUSSION}

Results shown in the following table indicate that chilling greatly reduced the budburst time in sycamore $(p<0.001)$ and pecan $(p=0.012)$ but not in sweetgum $(p=0.089)$. Because the data distribution was skewed toward early budburst dates, we used separate Kruskal-Wallis analyses for each species to obtain these values (IBM SPSS 2011). All three species burst their buds quickly following six weeks of chilling. Budburst of unchilled sycamore and pecan buds were significantly delayed while unchilled sweetgum buds burst quickly after exposure to warm temperatures.

Table Mean number of days of exposure to warmth that induced budburst in three species of trees in southeast Oklahoma. Values in parentheses indicate the number of twigs that were exposed to different levels of the treatment $\left(=\right.$ chilling). Asterisk $\left(^{*}\right)$ indicates significant difference using Kruskal-Wallis test at $p<0.05$.

\begin{tabular}{|c|c|c|c|c|}
\hline \multicolumn{7}{|c|}{ Weeks of chilling } \\
\hline Species & Zero & Three & Six & $p$-value \\
\hline Liquidambar styraciflua & $26.3(7)$ & $29.8(9)$ & $24.7(6)$ & 0.089 \\
\hline Platanus occidentalis & $63.0(6)$ & $38.0(10)$ & $21.3(9)$ & $0.001 *$ \\
\hline Carya illinoinensis & $53.3(6)$ & $32.6(10)$ & $23.4(9)$ & $0.012^{*}$ \\
\hline
\end{tabular}

\section{DISCUSSION}

The data confirmed the association between time of budburst and chilling enhancement, based on Oklahoma specimens of three tree species. We would expect sweetgum to respond the most to warmer winters. Gunderson et al. (2012) reported that experimentally-imposed warmer temperatures caused earlier budburst in sweetgum than in three other tree species, consistent with our results.

Global climate change has been associated not only with earlier spring budburst in deciduous trees but also earlier flowering in spring wildflowers and earlier spring activity in many kinds of animals (Miller-Rushing et al. 2008; Willis et al. 2008; Primack 2014). The extent to which different species respond to global climate change may alter the species makeup of an ecological community (Miller-Rushing and Primack 2008). If future global climate change should cause forests in the southern United States, such as those in southern Oklahoma, to have very mild winters, not all deciduous tree species will continue their trend toward earlier budburst. Instead, some tree species—-such as the sycamores and pecans in this study - may reverse their trend toward earlier budburst and instead have later budburst. Flexibility of phenological response appears to be an important contributor to survival in a world of global climate change. The eventual loss of chilling temperatures may alter the relative growth patterns of deciduous tree species in Oklahoma. 


\section{ACKNOWLEDGEMENT}

The authors would like to thank an anonymous reviewer for helpful comments and suggestions for this manuscript.

\section{REFERENCES}

Chuine, I. 2000. A unified model for budburst of trees. Journal of Theoretical Biology 207(3):337-347.

Globe.gov 2014. Budburst protocol. http://www.globe.gov/documents/356 823/2538681/earth prot budburst.pdf. Accessed 19 June 2014.

Gunderson, C.A., N.T. Edwards, A. V. Walker, K.H. O’Hara, C.M. Campion, and P.J. Hanson. 2012. Forest phenology and a warmer climategrowing season extension in relation to climatic provenance. Global Change Biology 18(6):2008-2025.

Heide, O.M. 1993a. Dormancy release in beech buds (Fagus sylvatica) requires both chilling and long days. Physiologica Plantarum 89(1):187-191.

Heide, O.M. 1993b. Daylength and thermal time responses of budburst during dormancy release in some northern deciduous trees. Physiologia Plantarum 88(4):531-540.

Hewett, P.F. and E.W. Wareing. 1973. Cytokinins in Populus $\times$ robusta: Changes during chilling and bud burst. Physiologia Plantarum 28(3):393-399.

Hunter, A.F. and M.J. Lechowicz. 1992. Predicting the timing of budburst in temperate trees. Journal of Applied Ecology 29(3):597-604.

Ibáñez, I., R.B. Primack, A.J. MillerRushing, E. Ellwood, H. Higuchi, S.D. Lee, H. Kobori, and J.A. Silander. 2010. Forecasting phenology under global warming. Philosophical Transactions of the Royal Society B365:3247-3260.

IBM Corp. Released 2011. IBM SPSS Statistics for Windows, Version 20.0. Armonk, NY: IBM Corp.
Kuden, A.B., O. Tuzcu, S. Bayazit, B. Yildirim, and B. Imrak. 2013. Studies on the chilling requirement of pecan nut (Carya illinoensis Koch) cultivars. African Journal of Agricultural Research 8(24):31593165.

Liang, L., M.D. Schwartz, and S. Fei. 2011. Validating satellite phenology through intensive ground observation and landscape scaling in a mixed seasonal forest. Remote Sensing of Environment 115:143-157.

Luedeling, E., E.H. Girvetz, M.A. Semenov, and P.H. Brown. 2011. Climate change affects winter chill for temperate fruit and nut trees. PLoS ONE 6(5):e20155.

Miller-Rushing, A.J., R.B. Primack, D. Primack, and S. Mukunda. 2006. Photographs and herbarium specimens as tools to document phenological changes in response to global warming. American Journal of Botany 93(11):16671674.

Miller-Rushing, A.J. and R. B. Primack. 2008. Global warming and flowering times in Thoreau's Concord: A community perspective. Ecology 89(2):332-341.

Miller-Rushing, A.J., T.L. Lloyd-Evans, R.B. Primack, and P. Satzinger. 2008. Bird migration times, climate change, and changing population sizes. Global Change Biology 14(9):1959-1972.

Morin, X., M.J. Lechowicz, C. Augspurger, J. O'Keefe, D. Viner, and I. Chiune. 2009. Leaf phenology in 22 North American tree species during the 21st century. Global Change Biology 15(4):961975.

Polgar, C.A. and R.B. Primack. 2011. Leafout phenology of temperate woody plants: From trees to ecosystems. New Phytologist :doi: $10.1111 /$ j.14698137.2011.03803.x.

Primack, R.B. 2014. W alden Warming: Climate Change Comes to Thoreau's Woods. [Chicago]: University of Chicago Press. 
Primack, D., C. Imbres, R.B. Primack, A.J. Miller-Rushing, and P. Del Tredici. 2004. Herbarium specimens demonstrate earlier flowering times in response to warming in Boston. American Journal of Botany 91(8):12601264.

Schwartz, M.D. 1994. Monitoring global change with phenology: The case of the spring green wave. International Journal of Biometeorology 38(1):18-22.

Schwartz, M.D., R. Ahas, and A. Aasa. 2006. Onset of spring starting earlier across the Northern Hemisphere. Global Change Biology 12:343-351.

Schwartz, M.D. and J.M. Hanes. 2010. Continental scale phenology: Warming and chilling. International Journal of Climatology 30:1595-1598.

Willis, C.G., B. Ruhfel, R.B. Primack, A.J. Miller-Rushing, and C.C. Davis. 2008. Phylogenetic patterns of species loss in Thoreau's woods are driven by climate change. Proceedings of the National Academy of Sciences USA 105(44):17,029-17,033. 